\begin{tabular}{|cc|}
\hline FIRES & SMOKE \\
BIOMASS & COMBUSTION \\
CONIFERS & ANGIOSPERMS \\
PHENOLS & LIGNIN \\
ANALYSIS & GC - MS \\
\hline
\end{tabular}

Open access revised manuscript version of

Chemosphere 41 (2000) 735-741

Link to publisher: doi:10.1016/S0045-6535(99)00427-0

\title{
Methoxyphenols from burning of Scandinavian forest plant materials
}

Jennica Kjällstrand, Olle Ramnäs and Göran Petersson

A basic analytical study was made for phenols from burning of wood Preceding research was done on volatile hydrocarbons from biomass burning 


\title{
METHOXYPHENOLS FROM BURNING OF SCANDINAVIAN FOREST PLANT MATERIALS
}

\author{
Jennica Kjällstrand, Olle Ramnäs and Göran Petersson* \\ Department of Chemical Environmental Science, \\ Chalmers University of Technology, \\ 41296 Göteborg, Sweden
}

\begin{abstract}
Semivolatile compounds in smoke from gram-scale incomplete burning of plant materials were assessed by gas chromatography and mass spectrometry. Gas syringe sampling was shown to be adequate by comparison with adsorbent sampling. Methoxyphenols as well as 1,6-anhydroglucose were released in amounts as large as $10 \mathrm{mg} / \mathrm{kg}$ of dry biomass at $90 \%$ combustion efficiency.

Wood, twigs, bark and needles from the conifers Norway spruce and Scots pine emitted twelve reported 2-methoxyphenols in similar proportions. Grass, heather and birchwood released the same 2-methoxyphenols but also the corresponding 2,6-dimethoxyphenols which are characteristic of angiosperms. The methoxyphenols are formed from lignin and differ in structure by the group in para position relative to the phenolic $\mathrm{OH}$ group. Prominent phenols were those with trans-1-propenyl and ethenyl groups in that position. Vanillin, 4-hydroxy-3-methoxybenzaldehyde, was a prominent carbonyl compound from the conifer materials.
\end{abstract}

Keywords: Phenols, wood, lignin, combustion, fire, smoke

\section{INTRODUCTION}

Assessment of the chemical components in smoke from biomass burning is important for both accidental and planned fires and with respect to both environmental impact and health hazards.

The lignin of vascular plants decomposes to fuel-specific methoxyphenols from biomass burning. Qualitative gas chromatographic and mass spectrometric data for 36 methoxyphenols from wood burning were recently presented [1], with references to earlier qualitative studies. The semivolatile monocyclic methoxyphenols are emitted as gases, and quantitative proportions have been reported from controlled analytical pyrolysis of wood and pulp [2]. At ambient temperatures, the methoxyphenols tend to condense, and they are present in extracts of smoke aerosols together with non-volatile compounds [3]. Small amounts of the most volatile methoxyphenols remain gaseous in smoke from different forest biomass materials [4]. 
The purpose of this study was to determine the amount and proportions of methoxyphenols released from natural forest materials. Different biomass materials, characteristic for Scandinavian boreal forests, were compared. Fire behaviour in these forests has been described in some detail [5].

\section{EXPERIMENTAL}

The plant materials were collected in interior south Sweden. The following data apply to biomass materials and experimental methods.

\section{Plant materials}

Softwood (Picea) : Pieces of fresh stem sapwood, cut from Norway spruce (Picea abies)

Twigs (Picea) : Needle-free thin twigs with bark, taken three months after felling

Softwood (Pinus) : Pieces of fresh stem sapwood, cut from Scots pine (Pinus sylvestris)

Bark (Pinus) : Thin stem and litter sheets from Scots pine

Needles (Pinus) : Season's upper litter needles from a 20-30 year old planted pine forest

Fern

Grass

Heather

Hardwood

: Stem and leaf pieces of dead winter-standing Pteridium aquilinum

Moss and lichen

\section{Fuels and burning}

Fuel preparation

Fuel drying

Fuel dry weight

: Pieces of dead straws of the common forest grass Deschampsia flexuosa

Amount of fuel.

: Twigs of Calluna vulgaris, with manually defoliated living parts

: Pieces of fresh stem sapwood, cut from white birch

Combustion pot

: The moss Pleurosium schreberi and the lichen Cladonia rangiferina were collected from pine forests

Covering pot

: Wood cut into thin chips and match-size pieces, other fuels broken to pieces

: Openly indoors for several days, bark and heather also for one hour at $100^{\circ} \mathrm{C}$

: In the range $90-95 \%$, determined by heating at $105^{\circ} \mathrm{C}$ to constant weight

Burning sequence

: In the range $1 \mathrm{~g}$ (fern, grass) to $10 \mathrm{~g}$ (softwood, hardwood)

: Ceramic, 1.51 , with the pile of plant material on the bottom

\section{Determination of $\mathrm{CO}$ and $\mathrm{CO}_{2}$}

Smoke sampling : 30-40 ml, gas-tight syringe (50 ml, SGE)

Gas chromatograph : Perkin Elmer $3920 \mathrm{~B}$, with gas sampling valves, $190 \mu 1(\mathrm{CO})$ and $290 \mu 1\left(\mathrm{CO}_{2}\right)$

Separation of CO : Molecular sieve $13 \mathrm{X}, 1.7 \mathrm{~m} \times 3.2 \mathrm{~mm}$ o.d. column, $80^{\circ} \mathrm{C}$, isothermal

Separation of $\mathrm{CO}_{2} \quad$ : HayeSep Q (60-80 mesh) porous polymer, $1.9 \mathrm{~m} \times 3.2 \mathrm{~mm}$ o.d. column, $80^{\circ} \mathrm{C}$

Detector

Calibrations

: Thermal conductivity, $200{ }^{\circ} \mathrm{C}, 150 \mathrm{~mA}$, carrier gas helium, $25 \mathrm{ml} \mathrm{min}^{-1}$

\section{Determination of methoxyphenols}

Smoke sampling $\quad: 400-500 \mu 1$, gas-tight syringe (500 $\mu 1$, SGE), pre-flushed with smoke 3-5 times

Gas chromatograph : Varian 3800 (MS-linked) with splitless injection $\left(220^{\circ} \mathrm{C}\right)$

Carrier gas

Column .

: Helium, $1.1 \mathrm{ml} \mathrm{min}{ }^{-1}$

Stationary phase

Oven temperature

: $30 \mathrm{~m} \times 0.25 \mathrm{~mm}$ i.d. FSOT (fused silica open tubular)

: Cyanopropylphenylsilicone, Rtx 1701, $0.25 \mu \mathrm{m}$ stationary phase layer

Mass spectrometer

Mass spectra

: Increased $5^{\circ} \mathrm{C} \mathrm{min}$ min $^{-1}$ from to $200^{\circ} \mathrm{C}$ and then kept isothermal at $200{ }^{\circ} \mathrm{C}$

Quantitative data

: Varian Saturn 2000 , ion trap $\left(150^{\circ} \mathrm{C}\right), \mathrm{EI}(70 \mathrm{eV})$

: Mass range $m / z$ 35-400, 1 spectrum $\mathrm{s}^{-1}$ recorded and data-stored

: External calibration using guaiacol and vanillin 
Cartridge

Adsorbent

Samples

Sampling volumes

Biomass fuel

Open burning

Desorption
: Injector glass liner with a narrow restriction at the lower end

: Tenax TA, 60-80 mesh, $0.1 \mathrm{~g}$

: Withdrawn using a $10 \mathrm{ml}$ syringe connected with a teflon tube

: $1-2 \mathrm{ml}$ for pot burning and $5-10 \mathrm{ml}$ for open burning

: Needle-free thin spruce twigs with bark (Picea abies)

: On plate in fume-cupboard, flaming and glowing combustion

: Thermal, in the injector, temperature raised from $100^{\circ} \mathrm{C}$ to $220^{\circ} \mathrm{C}\left(60^{\circ} \mathrm{C} \mathrm{min}{ }^{-1}\right)$

The methoxyphenols were identified using recently published chromatographic and mass spectrometric data [1]. Retention times are given in Table 1 for the specific polar gas chromatographic column used in this work. Automatic integration of peak areas, manually adjusted when required due to incorrect baseline drawing, was used for quantitative assessments. A few minor methoxyphenols overlapped with other compounds in the chromatograms. Selected ion monitoring for specific prominent ions was then used to determine peak areas. The mass spectra of the methoxyphenols are all characterised by an abundant molecular ion and a few prominent ions from specific fragmentations [1]. The difference in total ion response between the assessed methoxyphenols should be less than $20 \%$, because they all have similar proportions between $\mathrm{C}, \mathrm{H}$ and $\mathrm{O}[6]$. The response was therefore set equal for all compounds to facilitate comparisons. The response of vanillin was determined using a reference solution in acetonitrile. The magnitude of the response was confirmed for guaiacol using gas injection. A reference amount of guaiacol was then evaporated in a glass container (50 1) from which the gas sample was taken.

Carbon monoxide was not resolved from methane on the molecular sieve column used. Methane was optionally assessed specifically by changing from thermal conductivity to flame ionisation detection. The proportion of methane was shown to be less than $10 \%$ for a wood smoke sample, as expected from other biomass studies [4]. No corrections for methane were therefore made for any of the carbon monoxide determinations.

\section{RESULTS AND DISCUSSION}

The data given in Table 1 summarise the results of the study and are arranged to permit comparisons between different smoke components as well as different biomass materials.

\section{Methoxyphenol proportions}

The conifer samples and the fern sample gave rise to 2-methoxyphenols only, whereas the angiosperm samples of grass, heather and hardwood gave rise to both 2-methoxyphenols and 2,6-dimethoxyphenols. The proportion of 2,6-dimethoxyphenols was very high (80\%) for birchwood and quite low (30\%) for the grass.

The formation and total proportion of 2,6-dimethoxyphenols reflect the long known characteristic lignin structures of angiosperm plants [7]. The lignins of conifers almost lack 2,6-dimethoxysubstituted units. 
Table 1. Basic analytical data for smoke from biomass burning. Proportions (\% weight) of prominent 2-methoxyphenols (Gu = guaiacyl, 4-hydroxy-3methoxyphenyl compounds) and 2,6-dimethoxyphenols (Sy = syringyl, 4-hydroxy-3,5-dimethoxyphenyl compounds).

\begin{tabular}{|c|c|c|c|c|c|c|c|c|c|c|}
\hline \multicolumn{2}{|c|}{-2} & $\begin{array}{l}\text { Softwood } \\
\text { Picea }\end{array}$ & $\begin{array}{l}\text { Twigs } \\
\text { Picea }\end{array}$ & $\begin{array}{l}\text { Softwood } \\
\text { Pinus }\end{array}$ & $\begin{array}{c}\text { Bark } \\
\text { Pinus }\end{array}$ & $\begin{array}{l}\text { Needles } \\
\text { Pinus }\end{array}$ & $\begin{array}{c}\text { Fern } \\
\text { Pteridium } \\
\end{array}$ & $\begin{array}{l}\text { Grass De- } \\
\text { schampsia }\end{array}$ & $\begin{array}{l}\text { Heather } \\
\text { Calluna }\end{array}$ & $\begin{array}{c}\text { Hardwood } \\
\text { Betula }\end{array}$ \\
\hline \multicolumn{2}{|c|}{$\begin{array}{l}\text { Combustion efficiency }(\%) \\
\text { molar ratio } \mathrm{CO}_{2} /\left(\mathrm{CO}_{2}+\mathrm{CO}\right)\end{array}$} & 91 & 89 & 92 & 97 & 87 & 91 & 96 & 89 & 89 \\
\hline \multicolumn{2}{|c|}{ Carbon dioxide $\left(\mathrm{g} \mathrm{m}^{-3}\right)$} & 13 & 19 & 36 & 23 & 16 & 44 & 45 & 59 & 31 \\
\hline \multicolumn{2}{|c|}{ Carbon monoxide $\left(\mathrm{g} \mathrm{m}^{-3}\right)$} & 0.9 & 1.5 & 2.0 & 0.5 & 1.6 & 2.7 & 1.1 & 4.6 & 2.3 \\
\hline \multicolumn{2}{|c|}{ 1,6-Anhydroglucose $\left(\mathrm{mg} \mathrm{m}^{-3}\right)$} & 40 & 150 & 130 & 120 & 630 & 150 & 130 & 40 & 60 \\
\hline \multicolumn{2}{|c|}{ 2-Methoxyphenols $\left(\mathrm{mg} \mathrm{m}^{-3}\right)$} & 70 & 290 & 150 & 270 & 160 & 90 & 190 & 28 & 70 \\
\hline \multicolumn{2}{|c|}{ 2,6-Dimethoxyphenols $\left(\mathrm{mg} \mathrm{m}^{-3}\right.$ ) } & - & - & - & - & - & - & 80 & 30 & 320 \\
\hline Gu/Sy Phenols & Retention (min) & \multicolumn{2}{|c|}{ Proportions (\%) } & . & & & & & & \\
\hline $\mathrm{GuH}$ & $12.55 / 20.82$ & 4 & 4 & 3 & 5 & 3 & 4 & $2 / 4$ & $3 / 9$ & $1 / 12$ \\
\hline $\mathrm{GuCH}_{3}$ & $15.48 / 23.21$ & 12 & 9 & 9 & 9 & 5 & 11 & $4 / 5$ & $4 / 8$ & $2 / 15$ \\
\hline $\mathrm{GuCH}_{2} \mathrm{CH}_{3}$ & $17.83 / 25.07$ & 2 & 3 & 2 & 4 & 2 & 4 & $1 / 0.5$ & $1 / 3$ & $0.5 / 4$ \\
\hline $\mathrm{GuCH}=\mathrm{CH}_{2}$ & $19.38 / 26.47$ & 9 & 13 & 11 & 19 & 12 & 20 & $24 / 5$ & $8 / 6$ & $3 / 11$ \\
\hline $\mathrm{GuCH}_{2} \mathrm{CH}=\mathrm{CH}_{2}$ & $20.03 / 26.92$ & 3 & 2 & 3 & 3 & 3 & 3 & $2 / 1$ & $1 / 3$ & $0.5 / 3$ \\
\hline $\mathrm{GuCH}=\mathrm{CHCH}_{3}(Z)$ & $21.50 / 28.12$ & 2 & 2 & 2 & 2 & 2 & 3 & $1 / 0.5$ & $1 / 1$ & $0.5 / 2$ \\
\hline $\mathrm{GuCH}=\mathrm{CHCH}_{3}(E)$ & $22.85 / 29.48$ & 19 & 20 & 29 & 22 & 19 & 22 & $19 / 6$ & $15 / 11$ & $5 / 17$ \\
\hline $\mathrm{GuCHO}$ & $23.32 / 30.10$ & 18 & 20 & 12 & 13 & 16 & 13 & $9 / 3$ & $5 / 4$ & $3 / 6$ \\
\hline $\mathrm{GuCH}_{2} \mathrm{CHO}$ & $24.85 / 31.23$ & 5 & 1 & 4 & 7 & 2 & 1 & $1 / 0.5$ & $1 / 1$ & $0.5 / 2$ \\
\hline $\mathrm{GuCOCH}_{3}$ & $25.37 / 31.83$ & 6 & 4 & 4 & 3 & 3 & 4 & $2 / 2$ & $2 / 2$ & $1 / 2$ \\
\hline $\mathrm{GuCH}_{2} \mathrm{COCH}_{3}$ & $26.63 / 33.12$ & 6 & 6 & 5 & 4 & 8 & 4 & $2 / 0.5$ & $2 / 2$ & $1 / 3$ \\
\hline $\mathrm{GuCH}=\mathrm{CHCHO}(E)$ & $32.83 / 45.07$ & 5 & 5 & 8 & 3 & 9 & 6 & $3 / 1$ & $1 / 0$ & $1 / 1$ \\
\hline Other methoxypheno & & 9 & 11 & 8 & 6 & 17 & 5 & $1 / 0$ & $3 / 2$ & $1 / 2$ \\
\hline
\end{tabular}

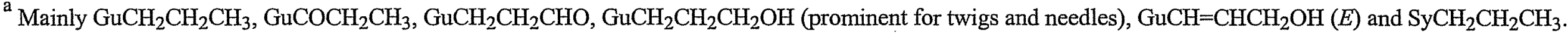




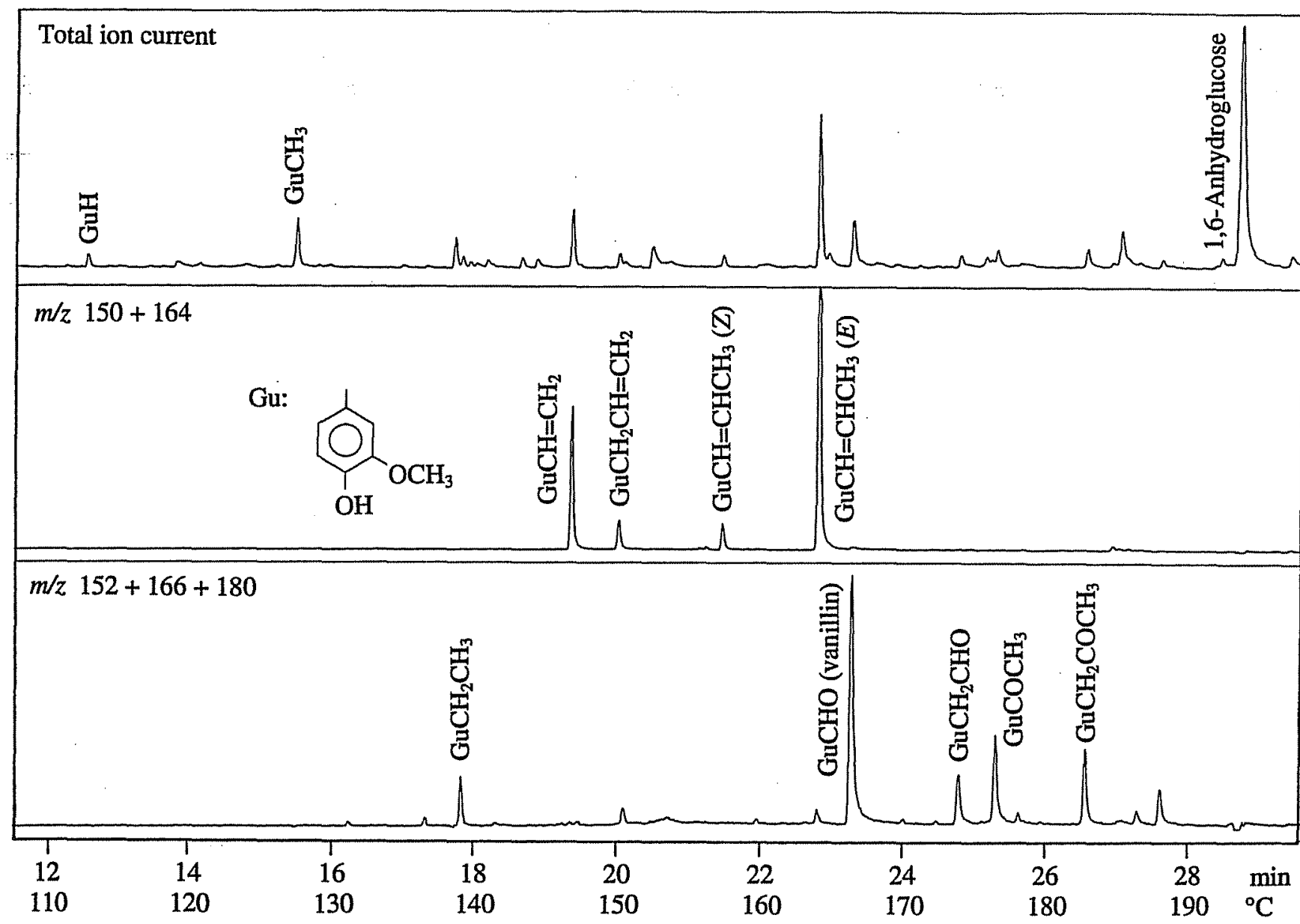

Fig 1. Chromatograms from GC-MS analyses of 4-hydroxy-3-methoxyphenyl (guaiacyl) compounds in smoke from pinewood burning (total ion current and ion currents corresponding to the molecular ions $m / z 150+164$ and $152+166+180$ ).

The observed absence from Pteridium of 2,6-dimethoxyphenols emphasises the fundamental evolutionary difference between ferns and angiosperms. Lignin is characteristic of vascular plants, and no methoxyphenols were obtained from burning of two common Scandinavian moss and lichen species.

Percentage proportions of total methoxyphenols are given in Table 1 for twelve specific 2-methoxyphenols and the corresponding twelve 2,6-dimethoxyphenols. As explained in Table 1, these are referred to as guaiacyl $(\mathrm{Gu})$ and syringyl (Sy) compounds with varying side chains. It is emphasised that the materials burn in different ways with respect to parameters such as temperature, flaming and glowing, which influence the proportions of phenols. Each material was allowed to burn uncontrolled which should reflect burning in forests better than pyrolysis and uniform burning conditions.

Guaiacol and its methyl and ethyl analogues ( $\mathrm{GuH}, \mathrm{GuCH}_{3}, \mathrm{GuCH}_{2} \mathrm{CH}_{3}$ ) were significant products from all nine materials with $\mathrm{GuCH}_{3}$ as the most prominent one. The corresponding Sy compounds were even more prominent relative to other Sy compounds.

The methoxyphenols with alkenyl side chains account for as much as $40-50 \%$ of total methoxyphenols for all materials. The species with trans-1-propenyl side chains tended to be predominant, but the ethenyl phenols were also very prominent. The well-known eugenol, $\mathrm{GuCH}_{2} \mathrm{CH}=\mathrm{CH}_{2}$, was formed in 
smaller amounts. In Figure 1, the four alkenyl phenols from sapwood of Scots pine are recorded by molecular ion monitoring below the total ion chromatogram.

The widely used food flavour additive vanillin, GuCHO, constitutes $10-20 \%$ of the recorded 2-methoxyphenols and was the major carbonyl-containing phenol. Vanillin is probably partly formed by oxidation of unsaturated side chains, and its percent proportion tended to increase with increased air supply. Other prominent 2-methoxyphenols with carbonyl groups were $\mathrm{GuCH}_{2} \mathrm{CHO}, \mathrm{GuCOCH}_{3}$ and $\mathrm{GuCH}_{2} \mathrm{COCH}_{3}$. In Figure 1, the presence and separation of these phenols in smoke from pine are illustrated by molecular ion monitoring. The prominent trans-coniferaldehyde, $\mathrm{GuCH}=\mathrm{CHCHO}(E)$, was the latest eluting 2-methoxyphenol. The Sy compounds with low volatility tended to be recorded in lower proportions than the corresponding Gu compounds.

\section{Sampling methods and combustion conditions}

The recorded methoxyphenols differ considerably with respect to polarity and reactivity of the side chain. To confirm the results, an optional method for sampling was developed. Samples were then taken on Tenax adsorption cartridges and the methoxyphenols were analysed after thermal desorption. Comparative results are given in Table 2 for the two very different methods. The results demonstrate similar methoxyphenol proportions for the two methods, without significant losses of the most polar and reactive carbonyl compounds, alkenes and alcohols. Somewhat lower proportions for syringe sampling are indicated only for the most volatile and chemically stable phenols, guaiacol and methylguaiacol.

The comparisons in Table 2 also demonstrate significantly different methoxyphenol proportions for differing burning conditions. Choked flaming burning causes elevated proportions of the alkenyl phenols. For glowing and smouldering combustion, an increased proportion of coniferaldehyde was observed. Adsorbent cartridges permit larger sampling volumes than gas injection and can therefore be used for smoke from open burning. The results in Table 2 for open burning compare well with the results from pot burning. It is concluded that the results in Table 1 approximately reflect the methoxyphenol composition in smoke from open burning.

Comprehensive qualitative studies of compounds from wood pyrolysis [8,9] include the reported methoxyphenols. Our qualitative results compare well with those reported from analytical pyrolysis of wood of the same spruce and birch species [2]. Apparently, oxidative pyrolysis conditions were applied in that study. Vanillin and other carbonyl compounds were even more prominent than in our results. In contrast, high proportions of alkenyl phenols but no carbonyl-containing phenols were reported from slow pyrolysis under nitrogen of wood from Salix, birch and spruce species [10]. A pyrolysis study of wheat straw lignin [11] reported low proportions of carbonyl compounds like vanillin. The major phenol was $\mathrm{GuCH}=\mathrm{CH}_{2}$, which was also the most prominent methoxyphenol from grass in our study. 
Table 2. Composition (\%) of methoxyphenols from spruce twigs. Comparison of differing burning conditions and sampling methods.

\begin{tabular}{|c|c|c|c|c|c|}
\hline & \multicolumn{2}{|c|}{ Choked pot burning } & \multicolumn{2}{|c|}{ Glowing pot burning } & \multirow{2}{*}{$\begin{array}{l}\text { Open burning } \\
\text { Cartridge }\end{array}$} \\
\hline & Syringe & Cartridge & Syringe & Cartridge & \\
\hline $\mathrm{GuH}$ & 5 & 9 & 5 & 10 & 7 \\
\hline $\mathrm{GuCH}_{3}$ & 6 & 11 & 6 & 9 & 10 \\
\hline $\mathrm{GuCH}_{2} \mathrm{CH}_{3}$ & 3 & 4 & 2 & 3 & 3 \\
\hline $\mathrm{GuCH}=\mathrm{CH}_{2}$ & 11 & 13 & 11 & 9 & 12 \\
\hline $\mathrm{GuCH}_{2} \mathrm{CH}=\mathrm{CH}_{2}$ & 4 & 3 & 2 & 3 & 2 \\
\hline $\mathrm{GuCH}=\mathrm{CHCH}_{3}(\mathrm{Z})$ & 3 & 2 & 2 & 2 & 2 \\
\hline $\mathrm{GuCH}=\mathrm{CHCH}_{3}(E)$ & 17 & 15 & 12 & 10 & 12 \\
\hline $\mathrm{GuCHO}$ & 11 & 11 & 13 & 13 & 13 \\
\hline $\mathrm{GuCOCH}_{3}$ & 8 & 6 & 5 & 4 & 5 \\
\hline $\mathrm{GuCH}_{2} \mathrm{COCH}_{3}$ & 8 & 6 & 7 & 5 & 6 \\
\hline $\mathrm{GuCH}_{2} \mathrm{CH}_{2} \mathrm{CH}_{2} \mathrm{OH}$ & 9 & 8 & 12 & 11 & 9 \\
\hline $\mathrm{GuCH}=\mathrm{CHCH}_{2} \mathrm{OH}(E)$ & 5 & 5 & 6 & 5 & 4 \\
\hline $\mathrm{GuCH}=\mathrm{CHCHO}(E)$ & 7 & 4 & 13 & 12 & 9 \\
\hline Other methoxyphenols ${ }^{\text {a }}$ & 3 & 3 & 4 & 4 & 6 \\
\hline
\end{tabular}

${ }^{a}$ Mainly $\mathrm{GuCH}_{2} \mathrm{CH}_{2} \mathrm{CH}_{3}, \mathrm{GuCH}_{2} \mathrm{CHO}, \mathrm{GuCOCH}_{2} \mathrm{CH}_{3}, \mathrm{GuCH}_{2} \mathrm{CH}_{2} \mathrm{CHO}$ and $\mathrm{GuCH}=\mathrm{CHCH}_{2} \mathrm{OH}(\mathrm{Z})$

Studies of methoxyphenols in smoke from biomass burning have been made mainly for particles and condensates. Smoke from residential wood stoves was reported to contain guaiacol and syringol as the most prominent methoxyphenols from softwood and hardwood [12]. Several alkenyl and carbonyl-containing methoxyphenols were observed in proportions similar to those given here, although the burning conditions were very different. Guaiacol and methylguaiacol were the most prominent among few methoxyphenols determined in condensates from burning of biomass related to ponderosa pine [4]. In contrast, carbonylcontaining methoxyphenols were observed to be the most prominent in fine particles from biomass burning $[3,13]$. For toxicity testing, semi-volatile compounds from wood burning have been collected on Tenax cartridges with subsequent solvent extraction [14].

\section{Smoke constituents}

From Table 1 it is seen that the $\mathrm{CO}_{2}$ concentration was typically $1-2 \%$ for the nine burning experiments: The $\mathrm{CO}$ concentration was typically $0.1-0.2 \%$ and the combustion efficiency consequently typically around $90 \%$.

The concentrations of methoxyphenols and other smoke components varied for the different plant materials, which were also burning in different ways. The highest 2-methoxyphenol concentrations were observed from pine bark and spruce twigs. The average amount of methoxyphenols relative to $\mathrm{CO}$ was as high as $10 \%$ for the softwood samples and even higher for the birchwood sample. These amounts of methoxyphenols relative to $\mathrm{CO}$ are at least ten times higher than the amounts reported for each of the major volatile organic compounds methane, ethane, methanol, and acetic acid from smouldering combustion of 
forest biomass [4]. They are also ten times higher than the recorded methoxyphenol levels, evidently due to a low recovery of these semivolatile compounds.

Approximately $1 \mathrm{~kg}$ of $\mathrm{CO}_{2}$ is formed from natural burning of $1 \mathrm{~kg}$ of forest biomass [4]. From the results in Table 1 it is concluded that the amount of released methoxyphenols was of the order $10 \mathrm{~g} / \mathrm{kg}$ of burnt biomass. Previously, the complex mixture of volatile hydrocarbons has been studied for biomass burning under similar conditions [15]. The ratio of total non-methane volatile hydrocarbons varied from 10 $\mathrm{g} / \mathrm{kg}$ for smouldering, to $0.1 \mathrm{~g} / \mathrm{kg}$ for flaming combustion of wood. Similarly increased emissions with decreased combustion efficiency have been reported for other volatile compounds emitted from forest biomass burning [4]. It is concluded that methoxyphenol emissions markedly exceeding $10 \mathrm{~g} / \mathrm{kg}$ are to be expected from the frequently occurring smouldering burning of lignin-containing forest biomass.

The predominant primary decomposition product from polysaccharides, 1,6-anhydroglucose, was formed in similar amounts as the total 2-methoxyphenols. In spite of its very polar nature with three alcoholic $\mathrm{OH}$ groups, satisfactory chromatographic performance was observed as illustrated in Figure 1 by the total ion chromatogram. Methoxyphenols and 1,6-anhydroglucose gave rise to all prominent recorded peaks from semivolatile compounds for most of the samples. This is illustrated in Figure 1 for the pinewood sample. Levoglucosan has been proposed as a tracer for smoke from biomass burning [16].

Condensation in the sampling syringe of 1,6-anhydroglucose and the methoxyphenols of low volatility was minimised by flushing the syringe with the hot smoke before sampling, and by injecting the sample within $30 \mathrm{~s}$ after sampling. Partial or complete losses of compounds of low volatility are likely to be a common source of errors in studies of methoxyphenols.

Many types of phenolic and other compounds of lower volatility than the methoxyphenols are released on burning, with immediate formation of smoke particles [3]. The semivolatile methoxyphenols are released as gases, but condense on the surface of particles as the temperature of the smoke decreases [12]. This means that the proportions of gaseous methoxyphenols in ambient air are biased towards the most volatile species.

\section{CONCLUSIONS}

The results demonstrate that methoxyphenols are formed in high concentrations and specific proportions from inefficient biomass burning. Syringe sampling immediately followed by GC-MS analysis permits adequate determination of the methoxyphenols in laboratory experiments. Adsorption on Tenax cartridges, followed by thermal desorption, is an optional method suitable also for field sampling.

The reported smoke components are indicative of emissions from accidental and planned forest fires and other inefficient biomass burning. A major environmental concern is the formation of ozone and other photo-oxidants from gaseous smoke constituents. The condensation of the methoxyphenols on particles decreases their contribution to ground-level ozone formation. Particles covered by adsorbed methoxyphenols and anhydrosugars should also have very different health effects compared with particles from traffic and other sources. 


\section{REFERENCES}

1. J. Kjällstrand, O. Ramnäs and G. Petersson, Gas chromatographic and mass spectrometric analysis of 36 lignin-related methoxyphenols from uncontrolled combustion of wood, $J$ Chromatogr $A$ 824, 205-210 (1998).

2. M. Kleen and G. Gellerstedt, Characterization of chemical and mechanical pulps by pyrolysis - gas chromatography / mass spectrometry, J Anal Appl Pyrolysis 19, 139-152 (1991).

3. B. R. T. Simoneit, W. F Rogge, M. A. Mazurek, L. J. Standley, L. M. Hildemann and G. R. Cass, Lignin pyrolysis products, lignans, and resin acids as specific tracers of plant classes in emissions from biomass combustion, Environ Sci Technol 27, 2533-2541 (1993).

4. L. M. McKenzie, W. M. Hao, G. N. Richards and D. E. Ward, Measurement and modeling of air toxins from smoldering combustion of biomass, Environ Sci Technol 29, 2047-2054 (1995).

5. J. Schimmel and A. Granström, Fuel succession and fire behavior in the Swedish boreal forest, Can $J$ For Res 27, 1207-1216 (1997).

6. W. L. Fitch, A. D. Sauter, Calculation of relative electron impact total ionization cross sections for organic molecules, Anal Chem 55, 832-835 (1983).

7. K. V. Sarkanen and H. L. Hergert, Classification and distribution, In Lignins Occurrence, Formation, Structure and Reactions (Edited by K. V. Sarkanen and C. H. Ludwig), Chap. 3. Wiley-Interscience, New York (1971).

8. A. D. Pouwels, A. Tom, G. B. Eijkel and J. J. Boon, Characterisation of beech wood and its holocellulose and xylan fractions by pyrolysis - gas chromatography - mass spectrometry, J Anal Appl Pyrolysis 11, 417 - 436 (1987).

9. O. Faix, D. Meier and I. Fortmann, Thermal degradation products of wood - Gas chromatographic separation and mass spectrometric characterization of monomeric lignin derived products, Holz Roh Werkstoff 48, 281-285 (1990).

10. A. Ingemarsson, M. Nilsson, J. R. Pedersen and J. O. Olsson, Slow pyrolysis of willow (Salix) studied with GC/MS and GC/FTIR/FID, Chemosphere 39, 103-112 (1999).

11. J. Rodríguez, M. J. Hernández-Coronado, M. Hernández, P. Bocchini, G. C. Galletti and M. E. Arias, Chemical characterization by pyrolysis / gas chromatography / mass spectrometry of acid-precipitable polymeric lignin (APPL) from wheat straw transformed by selected streptomyces strains, Anal Chim Acta 345, 121-129 (1997).

12. S. B. Hawthorne, M. S. Krieger, D. J. Miller and M. B. Mathiason, Collection and quantitation of methoxylated phenol tracers for atmospheric pollution from residential wood stoves. Environ Sci Technol 23, 470-475 (1989). 
13. W. F. Rogge, L. M. Hildemann, M. A. Mazurek, G. R. Cass and B. R. T. Simoneit, Sources of fine organic aerosol. 9. Pine, oak, and synthetic log combustion in residential fireplaces, Environ Sci Technol 32, 13-22 (1998).

14. A. Hauk, M. Sklorz, G. Bergmann and O. Hutzinger, Analysis and toxicity testing of combustion gases I. A new sampling unit for collection of combustion products, J Anal' Appl Pyrolysis 28, 1-12 (1994).

15. G. Barrefors and G. Petersson, Volatile hydrocarbons from domestic wood burning, Chemosphere 30, 1551-1556 (1995).

16. B. R. T. Simoneit, J. J. Schauer, C. G. Nolte, D. R. Oros, V. O. Elias, M. P. Fraser, W. F. Rogge and G. R. Cass, Levoglucosan, a tracer for cellulose in biomass burning and atmospheric particles, Atmos Environ 33, 173-182 (1999). 